\title{
Fractional measurements of sweat osmolality in patients with cystic fibrosis
}

\author{
E SIMMONDS, ${ }^{*}$ M ALFAHAM, ${ }^{*}$ R PROSSER, ${ }^{*}$ AND M D PENNEY $\dagger$ \\ Departments of ${ }^{*}$ Paediatrics and + Chemical Pathology, Royal Gwent Hospital, Newport
}

\begin{abstract}
SUMmARY After pilocarpine iontophoresis the change of sweat concentration during collection was studied by vapour pressure osmometry in 24 patients with cystic fibrosis and 24 healthy controls. There was a continuous but proportionate fall in sweat concentrations during the collection period. Mean (SD) initial sweat concentration in the control group was $154 \cdot 4(32 \cdot 6) \mathrm{mmol} / \mathrm{kg}$ falling, after $50 \mu \mathrm{l}$ of sweat produced, to $92.9(15 \cdot 8) \mathrm{mmol} / \mathrm{kg}$. In the cystic fibrosis group it was 315.9 $(35.8) \mathrm{mmol} / \mathrm{kg}$ falling to $247.4(24.9) \mathrm{mmol} / \mathrm{kg}$. Despite different rates of fall in concentrations, separation of the two groups was maintained throughout. We conclude that there are implications for the potential improvement of the predictive value of the sweat test.
\end{abstract}

The sweat test remains the most reliable laboratory procedure to confirm the clinical diagnosis of cystic fibrosis. ${ }^{12}$ Despite attempts to develop new procedures $^{3-5}$ the method of sweat collection and analysis used in most centres is still based on that originally described by Gibson and Cooke. ${ }^{6}$

Reliable diagnosis by this method requires that a volume of sweat exceeding a predefined minimum is collected to avoid analytical error. ${ }^{7} \mathrm{~A}$ recent study of the association between the sodium concentration and weight of sweat obtained by the Gibson and Cooke method in children with and without cystic fibrosis suggested that the predictive value of the test may be improved ${ }^{8}$; by plotting sweat weight against sodium concentration it was possible to separate the group with cystic fibrosis from the control group, when previously overlap had existed. Implicit from the analysis was that sweat sodium concentration is inversely related to the volume of sweat produced and that the concentration falls during the collection.

Developments in osmometry and sweat collection techniques have now made the direct measurement of sweat osmolality possible. ${ }^{9-11}$ The capillary sweat collection system (Macroduct), carried out as recommended by the manufacturers, collects sweat in fractions, but pools or cumulates the completed collection for analysis.

Using the Macroduct system the present study was carried out to determine if more diagnostic information could be obtained from fractional sweat concentrations than from the conventional procedure using pooled samples.

\section{Subjects and methods}

Twenty four patients who fulfilled the clinical criteria for cystic fibrosis and who had all previously been shown to have abnormal sweat test results by the method of Gibson and Cooke (minimum sweat weight $100 \mathrm{mg}$, sodium concentration $>60 \mathrm{mmol} / \mathrm{l}$, chloride concentration $>60 \mathrm{mmol} / \mathrm{l}$ ) were matched with 24 healthy control subjects. There were 11 boys and 13 girls with a mean age of 10.0 years (range 515 years) with cystic fibrosis, and the normal control group comprised 15 boys and nine girls with a mean age of 8.3 years (range 1-13 years). Ethical approval was granted by the South Gwent ethical committee.

Sweat collection was carried out using a modified Wescor Macroduct system (Chem Lab Instruments). The modification allowed the reuse of concave collector discs by replacing the central capillary tube with polythene tubing $0.8 \mathrm{~mm}$ diameter $\times 120$ $\mathrm{mm}$ (Hilger Analytical). Sweating was stimulated using $25 \mathrm{~mm}$ diameter $\times 5 \mathrm{~mm} 2 \%$ agarose in water discs containing $0.5 \%$ pilocarpine, and iontophoresis was induced for five minutes. After thorough cleaning of the skin, sweat was subsequently collected from the stimulation site for 30 minutes. The capillary tube was then gently clamped at both proximal (to the skin) and distal ends of the fluid using fine artery forceps and carefully removed from the 
collector disc. The tubing was placed on a level surface and the clamps released. Unfilled distal tubing was trimmed using a scalpel, and sweat was drawn from this end in $10 \mu \mathrm{l}$ aliquots with an automatic pipette. To minimise diffusion effects all measurements of osmolality were carried out within 30 minutes of collection using a precalibrated Wescor Vapour Pressure Osmometer 5500.

Statistical analysis was by unpaired Student's $t$ test, cumulative frequency analysis, and linear regression analysis.

\section{Results}

The individual values and amount of sweat collected (to the nearest complete $10 \mu \mathrm{l}$ ) are shown in fig 1 .

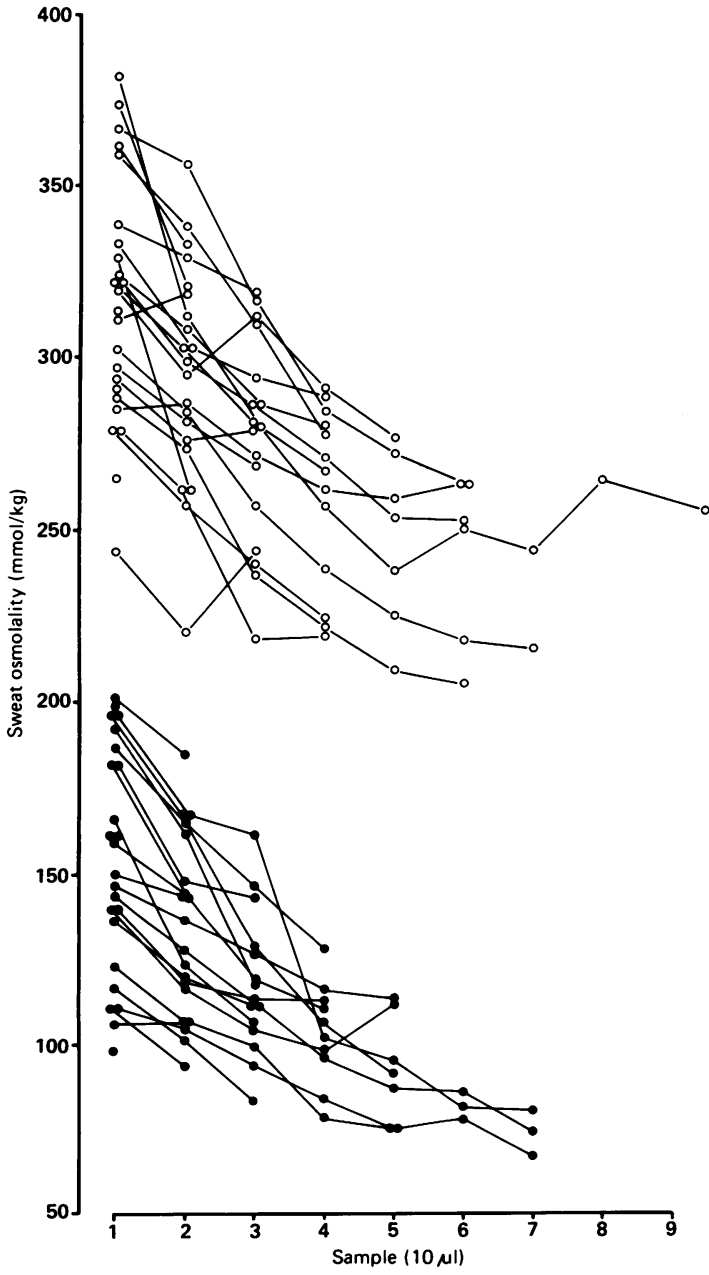

Fig 1 Fractional sweat osmolality measurements in normal children $(\mathrm{O})$ and children with cystic fibrosis $(\mathrm{O})$.
There was a consistent and significant fall in osmolality throughout the collection in both groups. As only the initial $10 \mu \mathrm{l}$ of sweat collected is common to all patients and controls the cumulative frequency distributions of the initial data on sweat osmolality are plotted in fig 2 . The data are normally distributed within both groups with complete and parallel separation.

The influence of sweat production rate (as measured by 30 minute volume) on the osmolality of the first aliquot of sweat was studied by linear regression analysis. No significant correlation in either group was established (cystic fibrosis group $r=0.04$, $p>0.05$; control group $r=0.08, p>0.05$ ).

It is possible to calculate the sweat osmolality

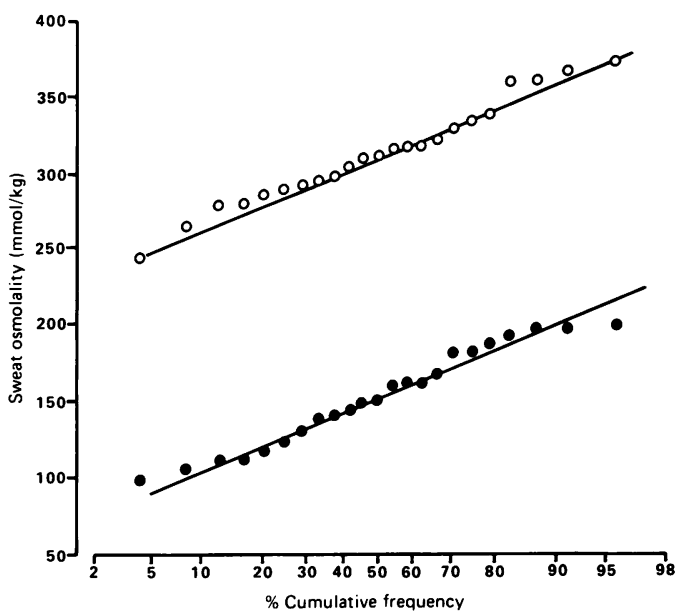

Fig 2 Cumulative frequency distribution of the osmolality measurement in the initial 10 ul of sweat collected from normal children $(\Theta)$ and children with cystic fibrosis $(O)$.

Table Sweat rates and osmolalities of both pooled sweat and the initial $10 \mu$ collected from 24 normal children and 24 children with cystic fibrosis. Values are expressed as mean $(S D)$

\begin{tabular}{|c|c|c|c|c|}
\hline & $\begin{array}{l}\text { Normal } \\
\text { children }\end{array}$ & $\begin{array}{l}\text { Children } \\
\text { with } \\
\text { cystic } \\
\text { fibrosis }\end{array}$ & $t$ & $\begin{array}{l}p \\
\text { Value }\end{array}$ \\
\hline $\begin{array}{l}\text { Sweating rate } \\
(\mathrm{ml} / \mathrm{min})\end{array}$ & $1 \cdot 14(0 \cdot 64)$ & $1.25(0.67)$ & 0.58 & $>0.5$ \\
\hline $\begin{array}{l}\text { Osmolality of } \\
\text { pooled sweat } \\
\text { Range }\end{array}$ & $\begin{array}{c}134 \cdot 2(31 \cdot 4) \\
88-199\end{array}$ & $\begin{array}{l}289 \cdot 4(31 \cdot 7) \\
236-348\end{array}$ & $17 \cdot 0$ & $<0.001$ \\
\hline $\begin{array}{l}\text { Osmolality of } \\
\text { initial sample } \\
\text { Range }\end{array}$ & $\begin{array}{l}154 \cdot 4(32 \cdot 6) \\
98-202\end{array}$ & $\begin{array}{l}315 \cdot 9(35 \cdot 8) \\
244-382\end{array}$ & $16 \cdot 3$ & $<0.001$ \\
\hline
\end{tabular}


result that would have been obtained in an individual subject by the conventional procedure of pooling sweat before analysis-this is simply achieved by calculating the mean result of all the fractions. As observed, there is potential for overlap of the groups if the volume of sweat is not taken into account (that is, comparison of a patient with cystic fibrosis who produced a large volume of sweat and a normal control subject who produced only a small volume). The difference between the range of sweat osmolality values obtained from the group with cystic fibrosis and that from the normal control group is highly significantly different on comparison of the

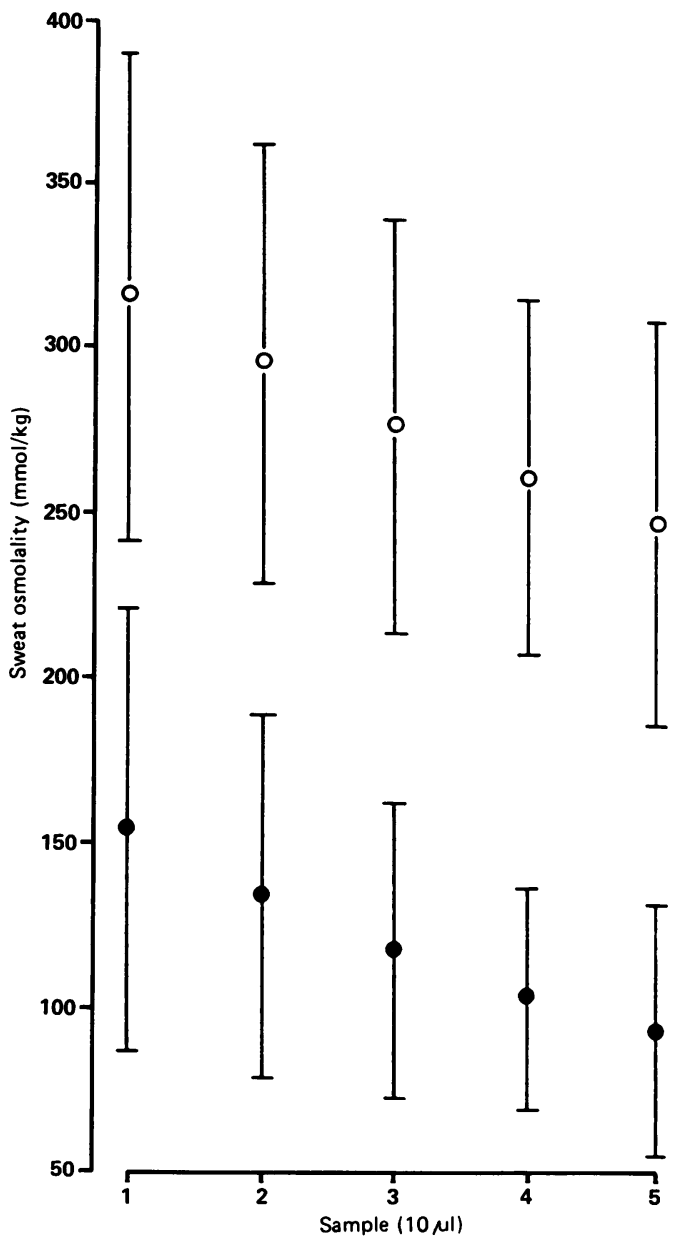

Fig 3 Mean and $95 \%$ confidence intervals of the sweat osmolality measurements for each of the first five fractions of sweat collected in normal children (O) and children with cystic fibrosis (O).

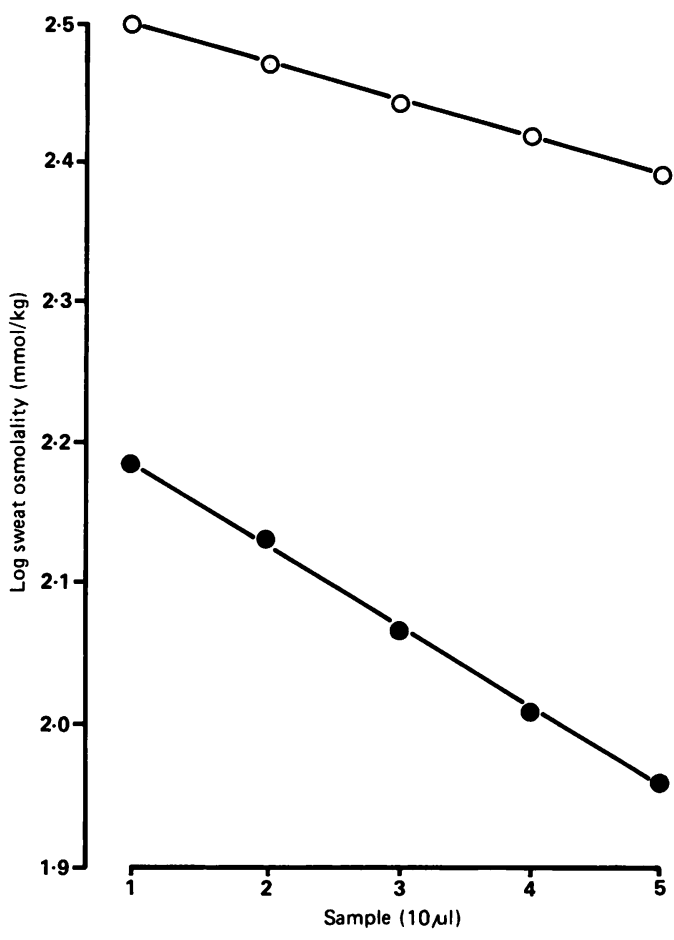

Fig 4 Rate of reduction of mean sweat osmolality (log scale) and sweat volume collected in normal children (O) and children with cystic fibrosis $(\mathrm{O})$.

calculated pooled osmolality values (table). The significance is not further enhanced by examination of the initial $10 \mu \mathrm{l}$ sweat volume fraction, but by analysis of the subsequent sweat concentrations better separation and improved significance can be achieved. Fig 3 shows the mean and $95 \%$ confidence intervals of the individual fraction values dependent on volume of sweat produced for the first five fractions. With each successive aliquot of sweat produced the two groups separate. The sweat concentration in either group reduces in a proportional or first order manner. The rate of reduction of log mean sweat osmolality with sweat volume is greater in the control group than in the group with cystic fibrosis (fig $4)$, hence the improved separation is achieved.

\section{Discussion}

There is increasing evidence that measurement of sweat osmolality is a reliable method for the diagnosis of cystic fibrosis. Our results of pooled individual data would concur with the range of diagnostic values established by others. ${ }^{9-11}$ In the two groups 
studied we have shown that there is clear diagnostic separation. This parallel separation of cumulative frequency plots of initial sweat osmolality is, as far as we are aware, the first time that the influence of volume on the concentration achieved has been excluded.

The production of sweat in fractions has permitted the study of changes in sweat concentration with volume. There is a dramatic reduction in sweat concentration as the volume of sweat that is produced increases, and thus the origin of potential overlap of groups is apparent. In practice, however, the use of the only consistent fraction between subjects-that is the first aliquot of sweat-as a discriminant of groups would not seem to offer an advantage over pooled sweat collected in the conventional manner. The reason for this is the fortuitous advantage of studying a pool rather than just one aliquot, accentuating the differing proportional rates of sweat osmolality reduction in the two groups. It should be emphasised, however, that separation has been achieved at all volumes of sweat. There is no obvious minimum sweat volume necessary for diagnostic discrimination and if this volume exists, it is currently dependent only on the restrictions of instrumentation.

How much longer the sweat test will remain as the basic diagnostic laboratory investigation for cystic fibrosis is open to conjecture now that molecular biology techniques are being developed. ${ }^{12-14}$ Irrespective of its long term role in this regard, however, we believe the changes in sweat concentration may have important implications for the application of sweat solute analysis for other metabolic disorders and in the overall understanding of the physiology of sweat production. For the near future the sweat test will continue as the laboratory investigation of choice to confirm the diagnosis.

In this study we have confirmed that measurement of sweat osmolality is a reliable analytical method. The need for only a small quantity of sweat means that problems in obtaining sweat in children who are poor producers of sweat, or in neonates, may be overcome. Moreover, we have shown that diagnostic difficulties resulting from borderline results may be overcome by a fractional technique and the application of appropriate reference inter- vals, particularly if high overall sweat volumes can be achieved.

We thank the paediatricians at the Royal Gwent Hospital, and Dr M Goodchild at the University Hospital of Wales, Cardiff, for permission to study their patients with cystic fibrosis, and the parents and children who took part in the study for their cooperation. We also acknowledge the assistance of the medical illustration department, and the expert secretarial help we had from the pathology department, Royal Gwent Hospital.

\section{References}

' Division of Medical Sciences, Assembly of Life Sciences, National Research Council, National Academy of Sciences, Washington DC. Report of the Committee for a Study for Evaluation of Testing for Cystic Fibrosis. J Pediatr 1975;88:711-50.

2 Littlewood JM. The sweat test. Arch Dis Child 1986;61:1041-3.

${ }^{3}$ Shwachman H, Dunham R, Phillips WR. Electrical conductivity of sweat. A simple diagnostic test in children. Pediatrics 1963;32:85-8.

+ Warwick WJ, Hansen L. The silver electrode method for rapid analysis of sweat chloride. Pediatrics 1965;36:261-4.

5 Mei V, Commellini L, Secciani L, Paulucci G. Total osmolality and principal osmoactive constituents of sweat in subjects with mucoviscidosis and their families. Boll Soc Ital Biol Sper 1966:42:1388-90.

' Gibson LE, Cooke RE. A test for concentration of electrolytes in sweat in cystic fibrosis of the pancreas utilizing pilocarpine by iontophoresis. Pediatrics 1959:23:545-9.

${ }^{7}$ Gibson LE. The decline of the sweat test. Clin Pediatr 1973;12:450-3.

* Hjelm M. Brown P. Bridden A. Sweat sodium related to amount of sweat after sweat test in children with and without cystic fibrosis. Acta Paediatr Scand 1986:75:652-6.

${ }^{9}$ Webster HL, Barlow WK. New approach to cystic fibrosis diagnosis by use of an improved sweat induction/collection system and osmometry. Clin Chem 1981;27:385-7.

10 Kirk JM, Adams A. Westwood A. McCrae WM. Measurement of osmolality and sodium concentration in heated-cup sweat collections for the investigation of cystic fibrosis. Ann Clin Biochem 1983;20:369-73.

"Carter EP, Barrett AD, Heeley AF, Kuzemko JA. Improved sweat test method for the diagnosis of cystic fibrosis. Arch Dis Child 1984:59:919-22.

12 Knowlton RC, Haguenauss O, Buchwald M, et al. A polymorphic DNA marker linked to cystic fibrosis is located on chromosome 7. Nature 1985:318:380-2.

${ }^{13}$ White R. Woodward S. Dear M. A closely linked genetic marker for cystic fibrosis. Nature 1985:318:382-4.

it Wainwright B, Scambler P. Williamson R. Localisation of cystic fibrosis locus to human chromosome 7. Nature 1985;318:384-5.

Correspondence to Dr MD Penney. Department of Chemical Pathology, Royal Gwent Hospital, Newport, Gwent NPT 2UB.

Accepted 14 July 1989 